\title{
QSAR and Synthesis of a Novel Biphenyl Carboxamide Analogue for Analgesic Activity
}

Prasanna Datar*

Sinhgad Institute of Pharmacy, Narhe, Pune, Maharashtra, India

\begin{abstract}
A compound 2-(anilino)-1-(4-phenylphenyl)ethanone was synthesized by reaction between biphenyl acid chloride and aniline. The synthesized compound was screened for analgesic activity. The selection of the compound was on the basis of QSAR study performed on the biphenyl analogs having anti-inflammatory activity. 2D QSAR study using topological descriptors revealed the important features required for the design of new potent anti-inflammatory agent. QSAR equation found in present study had $r^{2}$ of 0.842 and internal predictivity of 0.69 . Using QSAR results a molecule was designed to have analgesic activity.
\end{abstract}

Keywords: MLR; Electrotopological indices; Biphenyl; Carboxamide; Analgesic; Anti-inflammatory

\section{Introduction}

An analgesic is used to relieve pain either by acting at the peripheral or central nervous systems; they include paracetamol (acetaminophen) and Non-Steroidal Anti-Inflammatory Drugs (NSAIDs) such as the salicylates, aryl acetic acids, anthranilic acid derivatives and propionic acid derivatives. In choosing analgesics, the severity of the pain and the type of pain such as neuropathic pain are taken into consideration. The WHO pain ladder, originally developed in cancer-related pain, is widely applied to find suitable analgesic drugs in a stepwise manner [1].

The exact mechanism of action of paracetamol/acetaminophen is uncertain, but it appears to be acting centrally rather than peripherally in the brain rather than in nerve endings. Aspirin and other NonSteroidal Anti-Inflammatory Drugs (NSAIDs) inhibit cyclooxygenases, leading to a decrease in prostaglandin production. This reduces pain and also inflammation. Paracetamol and aspirin have one aromatic center and other carboxyl group center as pharmacophoric feature [25].

Paracetamol has few side effects and is regarded as safe, although intake above the recommended dose can lead to liver damage, which can be severe and life-threatening, and occasionally kidney damage [68]. NSAIDs predispose to peptic ulcers, renal failure, allergic reactions, and occasionally hearing loss, and they can increase the risk of hemorrhage by affecting platelet function. The ulceration was thought to be due to presence of carboxyl group function $[9,10]$.

There are various biphenyl analgesics present in the market such as diflunisal and flurbiprofen. Diflunisal acts by inhibiting the production of prostaglandins [11], while flurbiprofen reduces the hormone that causes inflammation and pain in the body. Biphenyl-4-carboxylic acid has been reported for anti-inflammatory activity [12], antimicrobial activity [13,14], insecticidal [15], antidiabetic [16], cytotoxicity, leishmanicidal, trypanocidal and antimycobacterial activities [17]. 3D QSAR $[9,10]$, docking and pharmacophore modeling studies have been performed earlier on biphenyl compounds. The common scaffold in most of the NSAID's had two aromatic ring centers and one acidic center as pharmacophoric element. The presence of carboxyl group or any other acidic center was also found to be the cause of ulcerogenic property of NSAID's. Recently nonacidic molecules have been found to be effective NSAID that lack acidic function such as carboxyl group e.g. nabumetone.

Introduction of third aromatic center has lead to the development of COX-2 inhibitors for almost two decades. Recently in 2004, rofecoxib and valdecoxib were withdrawn from the market due to their report of cardiovascular side effects. Thus introducing third aromatic center has made the molecule to interact with other biological receptors leading to severe side effects.

In order to stand with the known importance of two aromatic ring centers, a series of compounds containing biphenyl nucleus, substituted with carboxamide linkage at position-2 was designed using QSAR study and synthesized to evaluate analgesic activity.

\section{Materials and Methods}

\section{D QSAR studies}

Training set was selected that spans a large chemical domain. The domain can be limited or diverse with respect to chemical to develop and evaluate methodology for increasing the reliability of QSAR predictions. Regardless of the diversity of the training data used it is important to realize that empirical QSAR models are only valid in the domain space in which they were trained and validated. Extrapolation of empirical models is dangerous and can lead to grossly erroneous model predictions [18]. Twenty five substituted direct analogues of flurbiprofen [4'-methylbiphenyl-2-(substituted phenyl) carboxamide derivatives] reported by Shah et al. [19] for anti-inflammatory activity, as shown in Table 1. Training set was selected by sphere exclusion method and manual selection using chemical diversity. Data set was distributed manually to find mean and was further divided into training set and test set such that test set distribution lies within the limits of training set. Training set consists of a total of seventeen molecules such as, $1,5,6,7,8,10,11,12,15,16,17,18,20,21,22,23,24$. While test set consists of eight molecules such as 2, 3, 4, 9, 13, 14, 19, 25 .

\section{Biological data}

Anti-inflammatory activity of these molecules was found reported [19] as percent inhibition required inhibiting rat paw edema induced by carrageenan. The activity was converted to logarithmic value (Log

*Corresponding author: Prasanna Datar, Sinhgad Institute of Pharmacy, Narhe, Pune 411041, Maharashtra, India, Tel: 91-9823-161-187; E-mail: d_pras_anna@rediffmail.com

Received January 21, 2015; Accepted January 20, 2015; Published January 25 2015

Citation: Datar P (2015) QSAR and Synthesis of a Novel Biphenyl Carboxamide Analogue for Analgesic Activity. Mod Chem appl 3: 148. doi:10.4172/23296798.1000148

Copyright: @ 2015 Datar P. This is an open-access article distributed under the terms of the Creative Commons Attribution License, which permits unrestricted use, distribution, and reproduction in any medium, provided the original author and source are credited. 
BA) as shown in Table 1.

\section{Experimental}

\section{Computational details}

All molecular modeling studies were carried out using VLife MDS 3.5 [20]. Structures were constructed and partial charges were assigned using the MMFF. The molecules were subsequently minimized using MMFF force field until a root mean square deviation of $0.001 \mathrm{kcal} / \mathrm{mol}$ $\AA$ was achieved.

\section{Calculation of descriptors}

Various molecular descriptors were calculated such as molecular weight, dipole moment, partition coefficient $(\mathrm{C} \log \mathrm{P})$, surface area descriptors, H-bond donor count, $\mathrm{H}$-bond acceptor count, ionization potential, electron affinity, electrotopological indices and topological distance indices.

The topological distance indices captures the bond distances between any two atoms in a molecule. This bond distances (T) are useful to find distance between heteroatoms $(\mathrm{H})$ and any other $(\mathrm{O})$ atoms in number of bond path distances (D) indicated as T_H_O_D. One can find such distances commonly occurred in active molecules. A comparison can be made of such records with inactive molecules. Electrotopological indices gives the sum of E-state of atom type occurred in a molecule [21]. Electrotopological indices can be calculated easily in less time and can be used for virtual screening of databases to find useful hits that comply with the requirement of query substructure. The query substructure can be represented as sequence of atom types and path distances. This approach for finding novel entities is much simpler than earlier 3D QSAR studies reported [19]. The reproducibility of 3D QSAR study requires alignment of molecules and occupying grid space. In comparison our study using electrotopological indices generates search key which would be applicable without limitations of alignment and $3 \mathrm{D}$ space.

Multiple Linear Regression (MLR) models were generated to find the relationship between response variable and various physicochemical, structural descriptors (as independent variables). Significant descriptors were chosen on the basis of statistical data of analysis. Inter-correlation between these descriptors was not beyond 0.5 to confirm the independence of the variables.

The predictive power of equations was validated by Leave-OneOut (LOO) cross-validation method. Standard deviation based on predicted residual sum of squares (SPRESS) and Standard Deviation of Error of Prediction (SDEP) were used to guide selection of variables.

The statistical quality of the developed equations was judged by the parameters like coefficient of determination $\left(\mathrm{r}^{2}\right)$, standard error of estimate (s), cross-validation $\mathrm{r}^{2}\left(\mathrm{q}^{2}\right)$, SPRESS and SDEP.

The QSAR model generated by any method should be predictive as well as statistically significant and robust. Therefore randomization test was performed for 100 runs by shuffling the activity column in each run. The $r^{2}$ generated from randomization was compared with the $r^{2}$ of equation 1 . The validity of the best model can be further checked by carrying out the effects of outlier detection by prediction diagnostics. The outlier can be identified by $\mathrm{Z}$ score value. $\mathrm{Z}$ score value is calculated by the following formula.

\section{$\mathrm{Z}$ score $=\left(\mathrm{x}-\mathrm{x} \_\right.$mean $) / \mathrm{s}$}

Where, initially the mean is subtracted from every value, then the mean-shifted values are divided by the standard deviation, s. Z score is a value that estimates in terms of the number of standard deviations the value is above or below the mean of a data set.

\section{Chemistry}

Melting points were determined on a VEEGO Melting Point digital (VMPD) apparatus and are uncorrected. The FT-Infrared spectra were recorded in $\mathrm{KBr}$ on Jasco 6100 FT-IR spectrometer. The TLC was performed for the intermediate compounds using the solvent system (Benzene $(4 \mathrm{ml})$ : n-Hexane (1ml)). Eddy's hot plate (Ugo Basile 7250) was used for analgesic activity. Acetic acid, CMC, syringe, stop watch, weighing pan, Eddy's hot plate method device.

\section{Step 1: Synthesis of bromoacetyl chloride}

Acetic acid $6 \mathrm{ml}(0.1 \mathrm{~mol})$ and thionyl chloride $12 \mathrm{ml}(0.4 \mathrm{~mol})$ are placed in $250 \mathrm{ml}$ flask equipped with magnetic stirrer and condenser with drying tube. The reaction mixture was stirred and heated at $70^{\circ} \mathrm{C}$ using heating mental for half an hour [22]. The flask was then cooled to room temperature and to this reaction mixture were added finely powdered N-bromo succinamide $13 \mathrm{~g}(0.2 \mathrm{~mol})$ along with thionyl chloride $12 \mathrm{ml}(0.1 \mathrm{~mol})$ and 4 drops of concentrated hydrochloric acid. The flask was again heated to $85^{\circ} \mathrm{C}$ for 1.25 hours and then the solvent was removed under reduced pressure at $61.2^{\circ} \mathrm{C}$ (uncorrected).

\section{Step 2: Preparation of 1-biphenyl-4-yl-2-bromoethanone}

In a $250 \mathrm{ml}$ three necked flask provided with a dropping funnel, a mechanical stirrer and a reflux condenser, $1.54 \mathrm{~g}(0.01 \mathrm{~mol})$ of biphenyl, $1.33 \mathrm{~g}(0.01 \mathrm{~mol})$ of finely powdered anhydrous aluminum chloride and $35 \mathrm{ml}$ of anhydrous carbon disulphide was placed. The dropping funnel was charged with $0.8 \mathrm{ml}(0.01 \mathrm{~mol})$ of pure bromoacetyl chloride and closed with a calcium chloride guard tube. The mixture was heated on a water bath until gentle reflux commenced and bromoacetyl chloride was added drop wise, the addition product made its appearance as a curdy mass when about three quarters of the bromoacetyl chloride was added. The reaction mixture was refluxed gently for an hour. The reaction mixture was then cooled and poured slowly with stirring on to crushed ice to which hydrochloric acid was added and stirred. The product was filtered and washed with water to remove traces of hydrochloric acid and dried. It was recrystallized from methanol.

\section{Step 3: Preparation of 2-(anilino)-1-(4-phenylphenyl) ethanone}

Aniline $5 \mathrm{ml}(0.02)$ and $10 \%$ sodium hydroxide $5 \mathrm{ml}$ solution was taken in volumetric iodine flask and biphenyl acyl bromide $2 \mathrm{ml}(0.5$ $\mathrm{ml}$ at a time) was added with constant shaking and cooling in water. Then warm the reaction mixture and shake for 20 min till odour of acid disappears. $\mathrm{pH}$ was checked after every $5 \mathrm{~min}$. Reaction mixture was made alkaline using alcoholic $10 \%$ sodium hydroxide ( $\mathrm{pH} 7-14)$ to get the solid product. The product was filtered and then washed with water. The product was recrystallized from aqueous ethanol $(1 \mathrm{ml}$ water +2 $\mathrm{ml}$ ethanol).

\section{Biological Methods}

\section{Animals}

Swiss albino mice of either sex weighing 20-25 g and wistar rats of 175-200 g were obtained from National Toxicological Centre, Pune, India which is approved breeder of laboratory animals. They were housed under standard environmental conditions of temperature (24 $\pm 1^{\circ} \mathrm{C}$ ) and relative humidity of $30-70 \%$. A $12: 12 \mathrm{~h}$ light dark cycle was followed. All animals had free access to water and standard pelleted laboratory animal diet. All the experimental procedures and protocols 


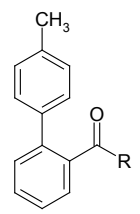

\begin{tabular}{|c|c|c|c|}
\hline S. No & $\mathbf{R}$ & $\begin{array}{l}\text { \%Reduction in paw } \\
\text { volume }^{\mathrm{a}}(100 \mathrm{mg} / \mathrm{kg})^{\mathrm{b}}\end{array}$ & $\log B^{c}$ \\
\hline 1 & $\langle\quad|-\mathrm{N}$ & 16.32 & 1.212 \\
\hline 2 & $-\mathrm{N}-$ & 31.63 & 1.500 \\
\hline $3^{*}$ & $\|\rangle_{-N}$ & 19.59 & 1.292 \\
\hline 4 & & 35.50 & 1.550 \\
\hline 5 & & 36.88 & 1.566 \\
\hline 6 & $N$ & 15.8 & 1.198 \\
\hline 7 & & 44.11 & 1.644 \\
\hline 8 & $\mathrm{H}_{2} \mathrm{~N}^{-}$ & 41.17 & 1.614 \\
\hline 9 & $-\mathrm{N}-$ & 39.70 & 1.598 \\
\hline 10 & $\mathrm{Cl}$ & 35.29 & 1.547 \\
\hline 11 & & 17.64 & 1.246 \\
\hline 12 & & 22.05 & 1.343 \\
\hline 13 & & 29.42 & 1.468 \\
\hline 14 & $N^{\prime \prime}$ & 24.90 & 1.396 \\
\hline 15 & $\mathrm{MeO}$ & 22.05 & 1.343 \\
\hline 16 & & 30.88 & 1.489 \\
\hline 17 & $\mathrm{O}_{2} \mathrm{~N}-\langle\mathrm{H}-$ & 40.48 & 1.607 \\
\hline
\end{tabular}


Citation: Datar P (2015) QSAR and Synthesis of a Novel Biphenyl Carboxamide Analogue for Analgesic Activity. Mod Chem appl 3: 148. doi:10.4172/2329-6798.1000148

Page 4 of 7

\begin{tabular}{|c|c|c|c|}
\hline 18 & ${ }_{11}^{\mathrm{HO}}$ & 23.80 & 1.376 \\
\hline 19 & & 19.52 & 1.290 \\
\hline 20 & $\mathrm{H}_{2} \mathrm{~N}-$ & 23.86 & 1.377 \\
\hline 21 & $\mathrm{HOOC}-\mathrm{N}-$ & 41.42 & 1.617 \\
\hline 22 & & 26.12 & 1.416 \\
\hline 23 & & 39.55 & 1.597 \\
\hline 24 & & 33.21 & 1.521 \\
\hline 25 & & 25.75 & 1.410 \\
\hline
\end{tabular}

${ }^{a}$ Carrageenan-induced rat paw edema model, using six animal group of male wistar rats ${ }^{b}$ Data analyzed by ANOVA followed Dunnetts test. $\mathrm{P}<0.05$

'Logarithm of percent reduction in paw volume

Table 1: In vivo anti-inflammatory activity of 4'-methylbiphenyl-2-carboxamide analogues

used in this study were reviewed and approved by the Institutional Animal Ethical Committee (IAEC) of College, Pune, constituted in accordance with the guidelines of the Committee for the Purpose of Control and Supervision of Experiment on Animals (CPCSEA), Government of India.

\section{Analgesic activity by hot plate method}

In hot plate method various responses (jumping and licking) were recorded. The control group of mice $(\mathrm{n}=6)$ received vehicle $(1 \% \mathrm{w} / \mathrm{v}$ CMC, $0.5 \mathrm{ml}$ p.o.). The test group mice received synthesized compound at 10,20 and $30 \mathrm{mg} / \mathrm{kg}$ p.o. and diclofenac $(9 \mathrm{mg} / \mathrm{kg}$ i.p.), respectively $[23,24]$. One hour following the test compound or diclofenac administration, the mice were individually placed on Eddy's hot plate (Ugo Basile 7250 ) maintained at $50-55^{\circ} \mathrm{C}$. The latency period of $20 \mathrm{sec}$ was defined as complete analgesia. To avoid injury, the measurement was terminated if latency period exceeded $20 \mathrm{sec}$.

\section{Writhing method}

The analgesic activity was determined by acetic acid induced writhing method using six albino mice (25-30 g) of either sex selected by random sampling technique [25]. Standard drug Aspirin (100 $\mathrm{mg} / \mathrm{kg}$ ) and synthesized compound, 2-(anilino)-1-(4-phenylphenyl) ethanone $(20 \mathrm{mg} / \mathrm{kg})$ were given intraperitoneally $30 \mathrm{~min}$ prior to the administration of the writhing agent $(0.6 \% \mathrm{v} / \mathrm{v}$ aqueous acetic acid, $10 \mathrm{ml} / \mathrm{kg}$ ). The number of writhing and stretching produced in the animal was observed for $30 \mathrm{~min}$. The numbers of writhing records were compared with the control drug.

\section{Results and Discussion}

\section{QSAR study}

The stepwise method during MLR method yielded significant QSAR equation. The statistically significant equation is given in Table 2 . The randomization $\mathrm{r}^{2}$ is much lower than the coefficient of determination $\left(\mathrm{r}^{2}\right)$, which indicates that the resultant QSAR equation is not by chance. The internal predictivity of the model is significant. Figure 1 gives the fitness plot of the equation 1 for predicted activity vs. actual activity. Predictivity of QSAR equation was assessed by predicting the activities of the test set molecules and the difference between predicted and actual activity values of the test set is given in Table 3 .

\section{Design of molecule}

Lipinski's rule of five suggests important features the molecule should have for its bioavailability. The series under consideration had $\mathrm{CH}_{3}$ group common on one side of biphenyl part which imparts bulk to the molecule and increases its size. Hence newly designed molecule did not have $\mathrm{CH}_{3}$ group at this end. The other side of the biphenyl has ortho substitution amide bond arm. This ortho substitution mimics the pharmacophore of COX-2 inhibitor. Therefore instead of ortho, substitution was made at para position. Since the amide bond is liable to break by amidases, it limits the duration of action of compound hence it was eliminated. Instead non-amide link was introduced to connect the third aromatic ring. MLR equation showed descriptor T_N_O_4, that gives the importance of distance between nitrogen and oxygen by 4 bond path length. This is true in reported compounds 4 and 18 . 
Citation: Datar P (2015) QSAR and Synthesis of a Novel Biphenyl Carboxamide Analogue for Analgesic Activity. Mod Chem appl 3: 148. doi:10.4172/2329-6798.1000148

Page 5 of 7

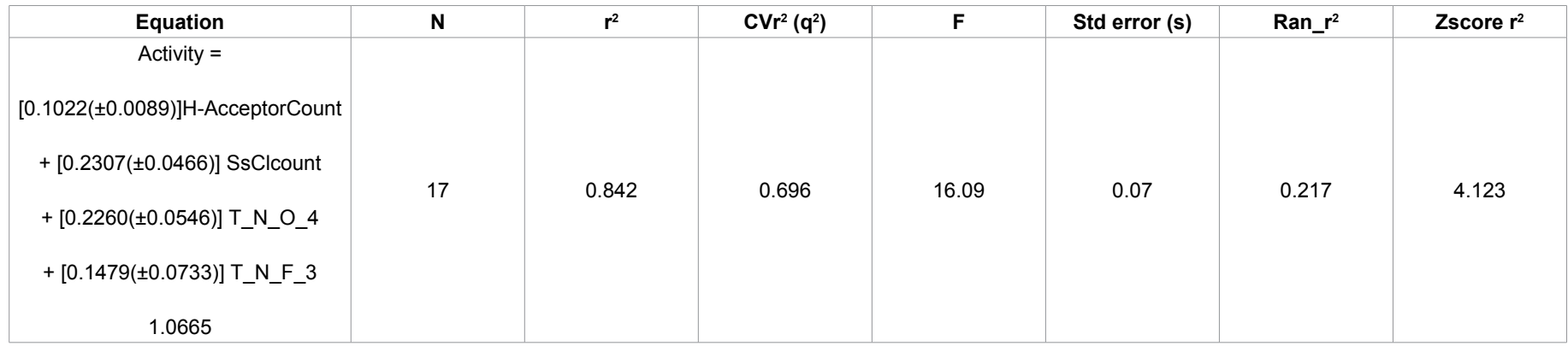

Table 2: Stepwise regression result using MLR method

\begin{tabular}{|c|c|c|c|}
\hline Compound & Actual activity & Predicted activity & Difference \\
\hline 02 & 1.500 & 1.270 & 0.229 \\
\hline 03 & 1.292 & 1.496 & -0.204 \\
\hline 04 & 1.55 & 1.927 & 0.463 \\
\hline 13 & 1.598 & 1.373 & 0.224 \\
\hline 14 & 1.468 & 1.270 & 0.197 \\
\hline 19 & 1.396 & 1.270 & 0.125 \\
\hline 25 & 1.290 & 1.373 & -0.083 \\
\hline
\end{tabular}

Table 3: The prediction of test set
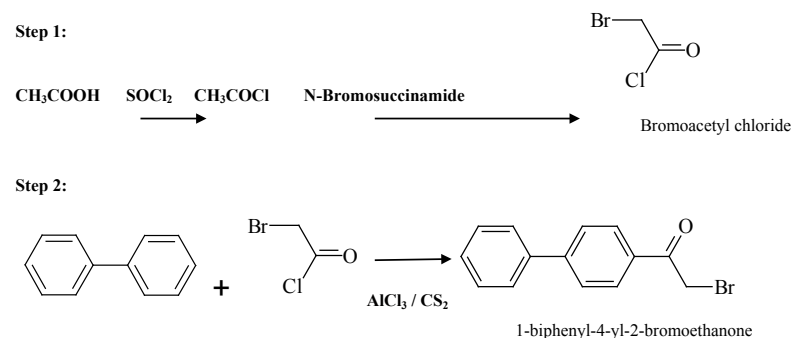

Step 3:

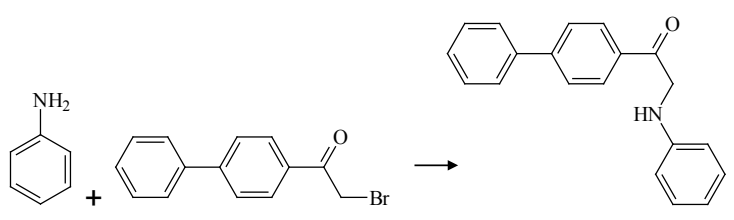

2-(anilino)-1-(4-phenylphenyl)ethanone

Figure 1: Scheme of synthesis of designed molecule, 2-(anilino)-1-(4phenylphenyl)ethanone

MLR equation also showed the importance of substituted $\mathrm{F}$ and $\mathrm{Cl}$ on the aromatic nucleus and their distance from nitrogen in descriptors SsClcount and T_N_F_3. But chlorine atom has higher van der Waals radius than fluorine. In the newly designed molecule chlorine and fluorine, both were eliminated to study the effect of prominence of the parameter. Instead of chlorine or fluorine, electronically rich and bulky aniline functional group was introduced (Figure 3). The MLR equation gives the importance of carbonyl group as hydrogen bond acceptor count. Hence looking at these input features the molecule was designed with para substitution keeping the distance between carbonyl oxygen and nitrogen by four and predicted from MLR equation 1 . The molecular modeling studies using systematic search method for identification of conformation showed that the third aromatic ring tilts away from axis that passes through biphenyl nucleus. The predicted value for the designed molecule was 1.5 , which is higher than lower active molecules.

\section{Characterization}

The designed molecule was synthesized by using scheme given in Figure 2 with percentage yield $68 \%$. The melting point of the compound (2-(anilino)-1-(4-phenylphenyl)ethanone) was $108^{\circ} \mathrm{C}$ (uncorrected). The FTIR gave the peak at 1680 for carbonyl group and $\mathrm{NH}$ peak at 3520 . The proton NMR gave the $\delta \mathrm{ppm}(\mathrm{m}, 7.4-7.8)$ for aromatic ring and $\delta$ ppm $(\mathrm{s}, 2.4)$ for $\mathrm{NH}$ group.

\section{Anti-inflammatory activity: In vivo activity}

Hot plate method: The responses of drug at $55^{\circ} \mathrm{C}$ on mice: In Eddy's hot plate method, the response time was noted as the time at which animals reacted to the pain stimulus either by paw licking or jump response, whichever appeared first as shown in Table 4.

The synthesized compound closely matches structurally to the drugs such as flurbiprofen and diflunisal mentioned as NSAIDs, therefore the standard utilized for the study was diclofenac. The synthesized compound is made into $1 \mathrm{mg} / \mathrm{ml}$ concentration as a stock solution and $0.1,0.2,0.3 \mathrm{ml}$ of this solution was injected peritonially to the mice. The licking and jumping responses showed that the drug with lowest concentration had maximum latency period than the dose of higher concentration. As seen in standard drug diclofenac administration, the response is of higher latency period.

\section{Writhing Method}

After administration of $0.6 \% \mathrm{v} / \mathrm{v}$ acetic acid the mice showed writhing action after $5 \mathrm{~min}$ in control group (Figure 3). It was found that the action of acetic acid is very irritating to mice. The records of observation of writhing are mentioned in the Table 5. After administration of Aspirin to mice as per dose $10 \mathrm{mg} / \mathrm{kg}$ of mice and then after $10 \mathrm{~min}$, the count of writhing was observed following administration of $0.6 \%$ acetic acid. The writhing movements were less than that of control acetic acid as shown in the Table 5 .

The second group of six mice of average weight $42 \mathrm{~g}$ were administered with synthetic compound in the dose of $20 \mathrm{mg} / \mathrm{kg}$ by oral route and the mice were kept for one hour. The responses after administration of 2-(anilino)-1-(4-phenylphenyl) ethanone (20 mg/kg) are also given in counts. The synthesized compound showed writhing response after $15 \mathrm{~min}$.

\section{Conclusion}

QSAR study has revealed useful equation in terms of topology and E-indices. The novelty of the designed molecule lies in absence of acidic character which was meant to be essential pharmacophoric feature for analgesic and anti-inflammatory activity. The synthesized compound showed moderate effect on central nervous system while in case of writhing method it was found that the synthesized compound has retention of analgesic activity. 
Citation: Datar P (2015) QSAR and Synthesis of a Novel Biphenyl Carboxamide Analogue for Analgesic Activity. Mod Chem appl 3: 148. doi:10.4172/2329-6798.1000148

Page 6 of 7

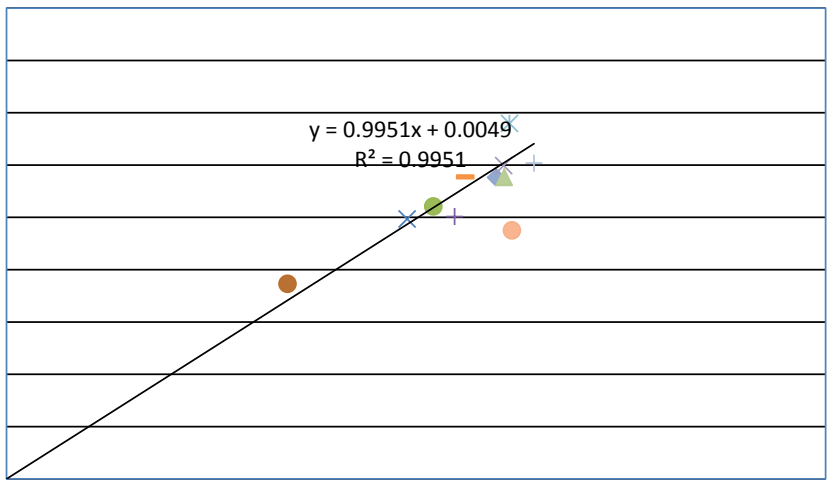

Figure 2: Predicted Vs actual anti-inflammatory activity for training set

\begin{tabular}{|c|c|c|c|c|}
\hline Animal & Weight of & $\begin{array}{c}\text { Response for } \\
\text { control group } \\
\text { mice }\end{array}$ & $\begin{array}{c}\text { Response for } \\
\text { compound } \\
\text { injected mice }\end{array}$ & $\begin{array}{c}\text { Response for } \\
\text { Diclofenac } \\
\text { injected mice }\end{array}$ \\
\hline animal & (in second) & (in second) & (in second) \\
\hline 2 & $44 \mathrm{~g}$ & $1 \mathrm{sec}$ & $3 \mathrm{sec}$ & $5 \mathrm{sec}$ \\
\hline 3 & $52 \mathrm{~g}$ & $2 \mathrm{sec}$ & $4 \mathrm{sec}$ & $4 \mathrm{sec}$ \\
\hline 4 & $48 \mathrm{~g}$ & $1 \mathrm{sec}$ & $3 \mathrm{sec}$ & $5 \mathrm{sec}$ \\
\hline 5 & $41 \mathrm{~g}$ & $1 \mathrm{sec}$ & $3 \mathrm{sec}$ & $4 \mathrm{sec}$ \\
\hline 6 & $47 \mathrm{~g}$ & $1 \mathrm{sec}$ & $3 \mathrm{sec}$ & $4 \mathrm{sec}$ \\
\hline & $44 \mathrm{~g}$ & $2 \mathrm{sec}$ & $3 \mathrm{sec}$ & $5 \mathrm{sec}$ \\
\hline
\end{tabular}

Table 4: The response of mice before and after administration of compound [2-(anilino)-1-(4-phenylphenyl)ethanone] $(1 \mathrm{mg} / \mathrm{ml})$, Diclofenac $(9 \mathrm{mg} / \mathrm{kg})$

\begin{tabular}{|c|c|c|c|c|c|c|c|}
\hline $\begin{array}{c}\text { Animal } \\
\text { number }\end{array}$ & $\begin{array}{c}\text { Weight } \\
\text { of } \\
\text { animal }\end{array}$ & $\begin{array}{c}\text { No. of writhes of } \\
\text { mice } \\
\text { for control group } \\
\text { (Acetic acid) }\end{array}$ & \multicolumn{2}{|c|}{$\begin{array}{c}\text { No. of writhes of } \\
\text { mice } \\
\text { (Aspirin) }\end{array}$} & \multicolumn{2}{|c|}{$\begin{array}{c}\text { No. of writhes of } \\
\text { mice } \\
\text { (compound) }\end{array}$} \\
\hline & & $0-10$ min & $\begin{array}{c}10-20 \\
\text { min }\end{array}$ & $0-10$ min & $\begin{array}{c}10-20 \\
\text { min }\end{array}$ & 0-10 min & $\begin{array}{c}10-20 \\
\text { min }\end{array}$ \\
\hline $\mathbf{1}$ & $44 \mathrm{~g}$ & 1 & 10 & 0 & 3 & 0 & 5 \\
\hline $\mathbf{2}$ & $48 \mathrm{~g}$ & 0 & 12 & 0 & 2 & 0 & 7 \\
\hline $\mathbf{3}$ & $52 \mathrm{~g}$ & 1 & 13 & 0 & 3 & 0 & 6 \\
\hline $\mathbf{4}$ & $41 \mathrm{~g}$ & 2 & 18 & 0 & 3 & 0 & 5 \\
\hline $\mathbf{5}$ & $44 \mathrm{~g}$ & 2 & 15 & 0 & 3 & 0 & 5 \\
\hline $\mathbf{6}$ & $45 \mathrm{~g}$ & 2 & 17 & 0 & 2 & 0 & 6 \\
\hline
\end{tabular}

Compound: Responses after administration of 2-(anilino)-1-(4-phenylphenyl) ethanone at oral dose of $20 \mathrm{mg} / \mathrm{kg}$

Table 5: Response of writhing response of mice to acetic acid, standard drug Aspirin and synthesized compound

\section{Acknowledgement}

Author thanks Mr. Anand Datar for providing facility and Sinhgad Institute of Pharmacy for organizing approval from animal ethical committee.

\section{References}

1. (1990) Cancer pain relief and palliative care. Report of a WHO Expert Committee. World Health Organ Tech Rep Ser 804: 1-75.

2. Dworkin $\mathrm{RH}$, Backonja $\mathrm{M}$, Rowbotham $\mathrm{MC}$, Allen $\mathrm{RR}$, Argoff $\mathrm{CR}$, et al. (2003) Advances in neuropathic pain: diagnosis, mechanisms, and treatment recommendations. Arch Neurol 60: 1524-1534.

3. Futaki N, Yoshikawa K, Hamasaka Y, Arai I, Higuchi S, et al. (1993) NS-398, a novel non-steroidal anti-inflammatory drug with potent analgesic and antipyretic effects, which causes minimal stomach lesions. Gen Pharmacol 24: 105-110.

4. Gans KR, Galbraith W, Roman RJ, Haber SB, Kerr JS, et al. (1990) Antiinflammatory and safety profile of DuP 697 , a novel orally effective prostaglandin synthesis inhibitor. J Pharmacol Exp Ther 254: 180-187.

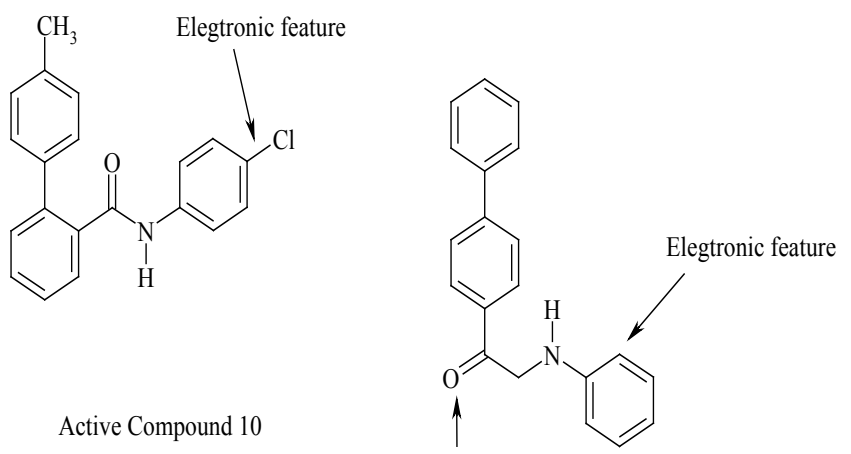

H-bond acceptor

Figure 3: Design perspective in developing biphenyl compound

5. Penning TD, Talley JJ, Bertenshaw SR, Carter JS, Collins PW (1997) Synthesis and biological evaluation of the 1,5-diarylpyrazole class of cyclooxygenase-2 inhibitors: identification of 4-[5-(4-methylphenyl)-3-(trifluoromethyl)-1H-pyrazol1-yl]benze nesulfonamide (SC-58635, celecoxib). J Med Chem 40: 1347-1365

6. Habeeb AG, Praveen Rao PN, Knaus EE (2000) Design and syntheses of diarylisoxazoles: Novel inhibitors of cyclooxygenase-2 (COX-2) with analgesicantiinflammatory activity. Drug Dev Res 51: 273-286.

7. Puig C, Crespo MI, Godessart N, Feixas J, Ibarzo J, et al. (2000) Synthesis and biological evaluation of 3,4-diaryloxazolones: A new class of orally active cyclooxygenase-2 inhibitors. J Med Chem 43: 214-223.

8. Kalgutkar AS, Crews BC, Rowlinson SW, Marnett AB, Kozak KR, et al. (2000) Biochemically based design of cyclooxygenase-2 (COX-2) inhibitors: facile conversion of nonsteroidal antiinflammatory drugs to potent and highly selective COX-2 inhibitors. Proc Natl Acad Sci U S A 97: 925-930.

9. Woods KW, McCroskey RW, Michaelides MR, Wada CK, Hulkower KI, et al (2001) Thiazole analogues of the NSAID indomethacin as selective COX-2 inhibitors. Bioorg Med Chem Lett 11: 1325-1328.

10. Kalgutkar AS, Marnett AB, Crews BC, Remmel RP, Marnett LJ (2000) Ester and amide derivatives of the nonsteroidal antiinflammatory drug, indomethacin, as selective cyclooxygenase-2 inhibitors. J Med Chem 43: 2860-2870.

11. Wallace JL (2008) Prostaglandins, NSAIDs, and gastric mucosal protection why doesn't the stomach digest itself? Physiol Rev 88: 1547-1565.

12. Deep A, Jain S, Sharma PC (2010) Synthesis and anti-inflammatory activity of some novel biphenyl-4-carboxylic acid 5-(arylidene)-2-(aryl)-4-oxothiazolidin-3yl amides. Acta Pol Pharm 67: 63-67.

13. Deep A, Jain S, Sharma PC, Verma P, Kumar M, et al. (2010) Design and biological evaluation of biphenyl-4-carboxylic acid hydrazide-hydrazone for antimicrobial activity. Acta Pol Pharm 67: 255-259.

14. Kannappan MAN, Deep A, Kumar P, Kumar M, Verma $P$ (2009) Synthesis and antimicrobial studies of biphenyl-4-carboxylic acid 2-(aryl)-4-oxo-thiazolidin-3$\mathrm{yl}$-amide. International Journal of Chem Tech Research 1: 1376-1380.

15. Plummer EL (1985) Insecticidal 2,2'-bridged(1,1'-biphenyl)-3-ylmethyl carboxamides. US patent 4493844

16. Sachan N, Thareja S, Agarwal R, Kadam SS, Kulkarni (2009) Substituted biphenyl ethanones as antidiabetic agents: Synthesis and in-vivo screening International Journal of PharmTech Research 1: 1625-1631.

17. de Souza AO, Hemerly FP, Busollo AC, Melo PS, Machado GM, et al. (2002) 3-[4'-bromo-(1,1'-biphenyl)-4-yl]-N, N-dimethyl-3-(2-thienyl)-2-propen-1-amine: synthesis, cytotoxicity, and leishmanicidal, trypanocidal and antimycobacterial activities. J Antimicrob Chemother 50: 629-637.

18. Eriksson L, Johansson E (1996) Multivariate design and modeling in QSAR Chemom Intell Lab Syst 34: 1-19.

19. Shah UA, Wagh NK, Deokar HS, Kadam SS, Kulkarni VM (2010) 3D-QSAR of biphenyl analogues as anti-inflammatory agents by genetic function approximation (GFA) [part-II]. International Journal of Pharma and Bio Sciences 1: $512-522$.

20. http://www.vlifesciences.com/products/VLifeMDS/Product_VLifeMDS.php 
Citation: Datar P (2015) QSAR and Synthesis of a Novel Biphenyl Carboxamide Analogue for Analgesic Activity. Mod Chem appl 3: 148. doi:10.4172/2329-6798.1000148

Page 7 of 7

21. Furniss BS, Hannaford AJ, Smith PWG, Tatchell AR (1989) Vogel's Textbook of Practial Organic chemistry. Fifth edition, Longman Group, UK, 723 pages.

22. Kulkarni SK (1999) Handbook of Experimental Pharmacology. 3rd revised edition, Vallabh Prakashan, New Delhi, India, 123-125.
23. Eddy NB, Leimbach D (1953) Synthetic analgesics. II. Dithienylbutenyl- and dithienylbutylamines. J Pharmacol Exp Ther 107: 385-393.

24. Witkin LB, Heubner CF, Galdi F, O'Keefe E, Spitaletta P, et al. (1961) Pharmacology of 2-amino-indane hydrochloride (Su-8629): a potent nonnarcotic analgesic. J Pharmacol Exp Ther 133: 400-408. 